To the Editors:

\title{
A case of Behcet's disease complicated with intra cardiac thrombus and Budd Chiari syndrome
}

\author{
Ceylon Medical Journal 2011; 56: 42-43
}

Mr. C, a 21-year old male, who had painful oral and genital ulceration for two years, came to us with a left blind eye due to panuveitis, generalised body swelling and painful abdominal distention of 1 week duration. He was diagnosed to be having Behcet's disease with pathergy test confirmation. He was anicteric. His cardiovascular, respiratory and neurological examinations were normal. He had tender ascites and extensive scrotal ulceration. Ultrasound scan of the abdomen revealed an enlarged liver with coarse echopattern with reduced portal venous flow velocity $(<10 \mathrm{ml} / \mathrm{sec})$. Central hepatic veins showed no blood flow. A contrast CT abdomen revealed inferior vena caval thrombosis involving all three hepatic veins. The portal vein appeared normal and the inferior vena cava reformed just above the right renal vein. These features confirmed Budd Chiari syndrome. A 2D echo showed a $30 \mathrm{~mm}$ elongated right atrial thrombus attached to the inter atrial septum. His serum AST was $58 \mathrm{u} / \mathrm{l}$, ALT was $44 \mathrm{u} / \mathrm{l}$, INR was 1.83 and APTT was 30 sec. Antinuclear antibody test and VDRL test were negative with no evidence of protein $C$ and $S$ deficiency.

He was started on enoxaparin $40 \mathrm{mg}$ and warfarin 3 mg daily aiming for an INR of 2-3. Oral prednisolone was started and tailed off with the introduction of azathioprine. A repeat 2D echo was performed after one month of treatment, and the right atrial thrombus had resolved.

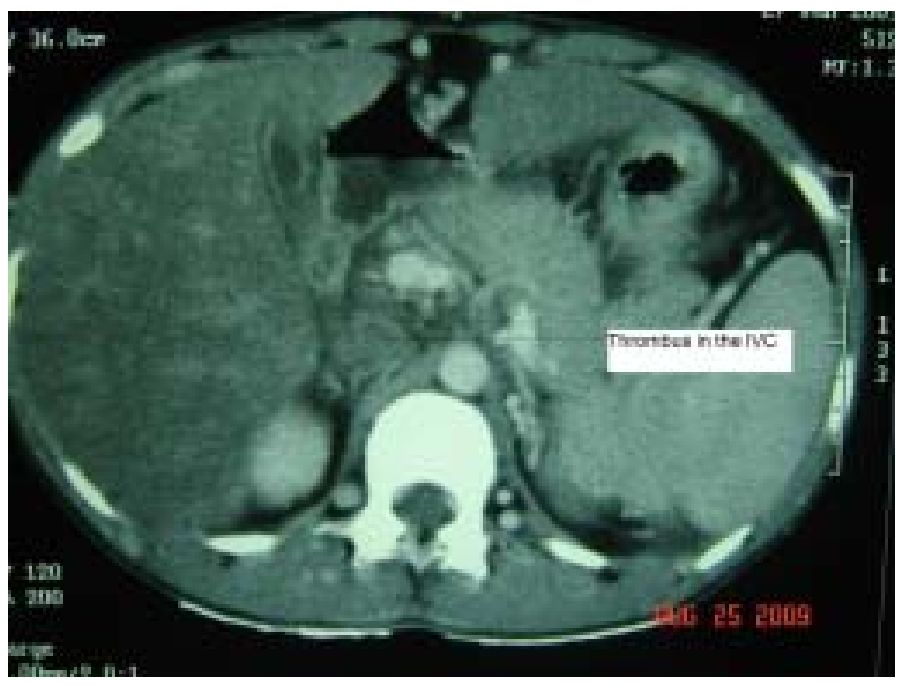

Figure 1. Hepatic vein thrombosis and hepatomegaly. 


\section{Discussion}

Though Behcet's disease is common in Turkey, Iran and Japan, it is rare in Sri Lanka. International diagnostic criteria include painful oral ulceration and any two of the following: genital ulcers, defined eye lesions (anterior or posterior uveitis, retinal vascular lesions), defined skin lesions (erythema nodosum, pseudofolliculitis, papulopustular lesions) and positive skin pathergy test.

Our patient had painful oral ulcers with panuveitis, genital ulcers and a positive pathergy reaction fullfilling the diagnostic criteria. It was complicated by a right atrial thrombus and Budd Chiari syndrome, which is the thrombosis of hepatic veins where Behcet's disease is a rare cause among many. It is well established that Behcet's disease predisposes to venous and arterial thrombosis and elevated Von Willebrand factor antigen levels have been demonstrated [1]. It is usually treated with anticoagulants. Interventional therapy such as angioplasty, stenting or TIPS (transjugular intrahepatic portocaval shunt) is performed if anticoagulation fails.

\section{S Thamotheram ${ }^{1}, \mathrm{~K}$ Thirumavalavan $^{1}$}

${ }^{1}$ Colombo North Teaching Hospital, Ragama, Sri Lanka.
Intracardiac thrombi usually involve the right side of the heart [2]. Its presence confirms a poor prognosis [3]. Anticoagulants and anti inflammatory drugs are effective in treating it [4].

\section{References}

1. Direskeneli H, Kesar G, D'Cruz D, et al. Anti endothelial cell antibodies, endothelial proliferation and Von Willebrand factor antigen in Behcet's disease. Clinical Rheumatology 1995; 14: 55-61.

2. Ugur GM, Haydar A, Melish K, et al. Intracardiac thrombus and co-existing pulmonary artery aneurism on Behcet's disease: two case reports. Turkish Respiratory Journal 2000; 4: 153-5.

3. Mogulkoc N, Burgess MI, Bishop PW. Intracardiac thrombus in Behcet's disease: a systematic review. Chest 2000; 118: 479-87.

4. Huong DL, Dolmazon C, De Zuttere D, et al. Complete recovery of right intraventricular thrombus and pulmonary arteritis in Behcet's disease. British Journal of Rheumatology 1997; 36: 130-2.

Correspondence: ST, e-mail <sthamotheram@yahoo.com>. Received 12 March and revised version accepted 3 July 2010. Competing interests: none declared. 